\title{
Determination of cation exchange capacity and exchangeable cations in soils by means of cobalt hexamine trichloride. Effects of experimental conditions
}

\author{
H Ciesielski *, T Sterckeman \\ With the technical help of M Santerne, JP Willery et d'r... \\ $2100:$ DWON CLOEX
FRANCE
}

Laboratoire d'analyses des sols, Inra, 273, rue de Cambrai, 62000 Arras, France

(Received 11 June 1996; accepted 13 November 1996)

\begin{abstract}
Summary - Different ways of using solutions of cobalt-hexamine $(\mathrm{Cohex})$ trichloride, $\left[\mathrm{Co}\left(\mathrm{NH}_{3}\right)_{6}\right] \mathrm{Cl}_{3}$, to determine the cation exchange capacity (CEC) and the quantity of exchangeable cations in soil samples are compared. First, various techniques for measuring the residual concentration of Cohex ions left in solution after the exchange reaction with soil are examined. Cobalt can be determined by flame atomic absorption spectrometry and ammonium nitrogen by spectrocolorimetry. However, a direct spectrocolorimetric determination of the coloured Cohex ions at $425 \mathrm{~nm}$ proves to be easier to carry out with a good repeatability, provided that non-specific absorptions have been properly corrected in advance. That method was retained to compare three procedures of ion exchange: single extraction, successive extractions and percolation. The latter study allows us to chose a particular procedure with a knowledge of its limitations, advantages and disadvantages. In spite of a slightly lower reaction yield, results obtained with a single extraction remain quite appropriate to quantify the magnitude of the exchange reactions.
\end{abstract}

soil analysis / cation exchange capacity / exchangeable cation / cobalt hexamine

Résumé - Détermination de la capacité d'échange et des cations échangeable dans les sols avec le chlorure de cobaltihexammine. Choix des conditions expérimentales. On décrit et compare différentes manières d'utiliser des solutions de chlorure de cobaltihexammine $\left[\mathrm{Co}\left(\mathrm{NH}_{3}\right)_{6}\right] \mathrm{CI}_{3}$ pour mesurer la capacité d'échange cationique (CEC) et les quantités de cations échangeables d'un échantillon de sol. On décrit dans un premier temps différentes techniques de dosage de l'ion cobaltihexammine en solution. Le cobalt peut être dosé par absorption atomique de flamme et l'ion ammonium par spectrocolorimétrie. Néanmoins, la spectrocolorimétrie directe des solutions de cobaltihexammine présente les avantages d'une grande simplicité de mise en œuvre et d'une bonne répétabilité, sous réserve que l'on s'affranchisse correctement des absorptions non spécifiques. Elle a été retenue pour comparer différentes procédures d'échange entre l'échantillon de sol et la solution de réactif : la simple agitation, les extractions successives et la percolation. Cette étude, en décrivant l'influence de certains paramètres expérimentaux importants, permet de justifier le choix d'une procédure particulière en précisant ses limites d'utilisation, ses avantages et ses inconvénients. Malgré un rendement légèrement plus faible, les résultats obtenus avec une simple agitation restent tout à fait appropriés pour mesurer l'amplitude des réactions d'échange.

analyse de sol / capacité d'échange cationique / cation échangeable / cobaltihexamine

* Correspondence and reprints.

Tel: (33) 03215992 24; fax: (33) 0321241408 


\section{INTRODUCTION}

There are numerous methods available for measuring the cation exchange capacity (CEC) of soils (Chapman, 1965; Rhoades, 1982). As with many other physical and chemical parameters, the CEC value is the result of a particular state of equilibrium between the test sample and a given environment, consisting of the reagent and the experimental conditions chosen. Depending on the method used, the impact of such factors as the nature of the cation being exchanged (called index cation), the ionic strength of the reagent solution, or the $\mathrm{pH}$ of the suspension, can vary greatly (Morais et al, 1976; Gillman et al, 1983). It is all the more complicated to discern their respective influences as the experimental procedures themselves can induce secondary phenomena affecting the specificity of the exchange mechanisms to a greater or lesser degree.

The Cohex ion is well-known to chemists. Its simple octahedral structure is often cited as an example to explain the respective roles of the $s, p$ and $d$ orbitals in chemical bonds in transition metals (Gray, 1969). Its earliest use as an index cation was described by Morel (1957). In 1976, Orsini and Remy (1996) adapted the method for agronomic use and Fallavier et al (1985) for tropical soils. It was standardized in France in 1985, as were the ammonium acetate (Metson, 1956) and the ammonium oxalate (Riehm et al, 1954) methods. Despite this, it remains little used today. The Cohex ion is stable $\left(\mathrm{pK}_{1}=4.4\right.$ and $\mathrm{pK}_{6}$ $=7.3$ ), and although relatively large (its ionic radius is $0.325 \mathrm{~nm}$ according to Morel, 1957), it exchanges easily and gives satisfactory results with little reagent excess. This facilitates the determination of the quantity of reagent fixed, since the difference between the initial and the residual concentrations remains relatively large. In contrast to other methods which require that the absorbed cation be further put back in solution, the measurement of the CEC with good precision is possible here with a so-called back titration. Cohex chloride is an unbuffered reagent and its use in solutions at low concentration $\left(0.01666 \mathrm{~mol} \cdot \mathrm{L}^{-1}\right)$ is an additional advantage, as such conditions are closer to natural soil conditions (Guadalix et al, 1988).

In the first part of this article we will examine different techniques for measuring the concentration of the Cohex ions in solution. Cobalt determination by flame atomic absorption spectrometry and ammonia nitrogen determination by spectrocolorimetry will be compared to a direct spectrocolorimetric determination at $475 \mathrm{~nm}$ without pretreatment of the solution.

The choice of procedure for ensuring the saturation of exchange sites in the soil is important; several ways for cation saturation will therefore be compared. We will investigate the impact of three methods on the CEC values and on the quantities of cations extracted: single extraction, successive extractions and percolation.

\section{MATERIALS AND METHODS}

\section{Soil samples}

Forty-eight soil samples collected in various regions of France (loamy soils from the north, granitic ones from Brittany, volcanic ones from the Massif Central, alluvials from the Rhineland, calcareous soils from Champagne) are studied. Their basic characteristics are listed in table I. These samples were air-dried and passed through a $2 \mathrm{~mm}$ sieve before being analyzed.

\section{Measurement methods}

Three methods were compared for measuring Cohex ion concentrations in solutions. The reagent used in this work is commercially available (Fluka, Buchs, Switzerland)

\section{Determination of ammonia nitrogen concentrations}

The initial concentration of the Cohex chloride solutions is of $5 \mathrm{cmol}+\cdot \mathrm{L}^{-1}$ which correspond to an ammonia nitrogen contents of $10 \mathrm{cmol} \cdot \mathrm{L}^{-1}$ The latter can be determined by spectrocolorimetry of an indophenol complex formed in basic $\mathrm{pH}$ conditions by the reaction of ammonia with a chlorinating agent and a phenol compound (Orsini and Remy, 1976). With this technique, for a measuring time of $30 \mathrm{~s}$ per sample, we have found relative standard deviations (RSD) of about $1 \%$, in the repeatability conditions.

\section{Determination of cobalt concentrations by flame atomic absorption spectrometry}

The initial concentration of cobalt in solution is about $1 \mathrm{~g} \cdot \mathrm{L}^{-1}$. As the composition of the solutions after contact with the soils remains relatively simple, the determination can be carried out without major interferences. Cobalt allows the use of numerous analytical lines of differing sensitivities, which offer great latitude in the choice of the dilution ratios. For 
Table I. Main characteristics of the soils used in the experiments.

\begin{tabular}{|c|c|c|c|c|c|}
\hline \multicolumn{2}{|c|}{ Clay $\left(g \cdot \mathrm{kg}^{-1}\right)$} & \multicolumn{2}{|c|}{ Carbon $\left(g \cdot k g^{-1}\right)$} & \multicolumn{2}{|c|}{$p H$ in water } \\
\hline Class & Frequency & Class & Frequency & Class & Frequency \\
\hline $0-100$ & 7 & $0-10$ & 17 & $4-5$ & 3 \\
\hline $100-200$ & 20 & $10-20$ & 13 & $5-6$ & 9 \\
\hline $200-300$ & 11 & $20-30$ & 8 & $6-7$ & 10 \\
\hline $300-400$ & 6 & $30-50$ & 5 & $7-8$ & 15 \\
\hline $400-600$ & 4 & $50-200$ & 5 & $8-8.3$ & 11 \\
\hline
\end{tabular}

Distribution according to clay content, organic carbon content and $\mathrm{pH}$ determined according to AFNOR standards X $31-107 . \mathrm{X} 31$ 109, X 31-103.

the tests described, we used a wavelength of $304.4 \mathrm{~nm}$. The extracts were diluted in water with a ratio of $1 / 10$. For a signal integration time of $12 \mathrm{~s}$, we achieved RSD of the order of $0.5 \%$ in the repeatability conditions.

\section{Determination of the Cohex ion concentrations by direct spectrocolorimetry}

The Cohex ion in solution has a maximum absorption at $475 \mathrm{~nm}$ and a minimum at $380 \mathrm{~nm}$. The molar extinction coefficients are, respectively, 56.0 and 6.9 $\mathrm{cm}^{2} \cdot \mathrm{mmol}^{-1}$. A spectrocolorimetric determination can be made without preliminary treatment of the extracts. However, a problem of specificity may appear owing to a slight dissolution of organic matter which likewise absorbs at $475 \mathrm{~nm}$. Measurements carried out on soil extracts obtained with a solution of $5 \mathrm{cmol}+\cdot \mathrm{L}^{-1}$ ammonium chloride have shown that the ratio of the optical density of the soluble organic matter at $475 \mathrm{~nm}$ divided by that at $380 \mathrm{~nm}$ can be considered constant and equal to 0.2 . For the pure Cohex ion, this ratio is 8.13. Consequently, a measurement at each of these wavelengths allows us to eliminate this interference, by determining its extent. With this method and for measuring times of $5 \mathrm{~s}$ at each wavelength, RSD of $0.2 \%$ have been obtained in the repeatability conditions. According to the $\mathrm{pH}$ of the extracts and the proportion of organic matter, the corrections, expressed in terms of CEC, fall between 0.1 and 1 $\mathrm{cmol}+\cdot \mathrm{kg}^{-1}$.

\section{Determination of the exchangeable cations}

Cation concentrations were measured by flame atomic absorption spectrometry for $\mathrm{Ca}$ and $\mathrm{Mg}$ or by flame atomic emission spectrometry for $K$. These determinations posed no particular problems, and after having adapted them to the characteristics of our extracts, we have applied the directives established by the AFNOR X 31-108 standard.

We did not consider sodium because of the low quantities of this cation generally encountered. Neither did we cover the issue of the exchange acidity, but it should be pointed out that Cohex chloride does not affect the titration of $\mathrm{H}^{+}$ions and aluminium.
Moreover, we consider the low ionic charge of the reagent solutions to be a further advantage, as it limits the dissolution of free aluminium oxides and hydroxides.

\section{Exchange methods}

Three exchange protocols were used on our series of samples.

\section{Method M1: single extraction}

With this method the exchange is achieved by simply shaking the test sample in the reagent. The operating conditions chosen by Orsini and Remy (1976) were such that the part of the reagent absorbed in comparison with the initial quantity fell between 0.15 and 0.33 . These limits were imposed, respectively, by too great an increase in the inaccuracy of the back titration when the quantity of reagent absorbed was too small, and by a significative fall in the exchange yield when this quantity was too high. They can be respected by varying the mass of the sample. keeping constant the volume and the concentration of the reagent. Direct spectrocolorimetry provides better repeatability of the measurements; it is thus possible to extend the use of the method of single extraction downwards, consuming lower proportions of reagent. We have fixed this lower part at 0.05 rather than 0.15 and for the upper limit we have slightly extended the recommended value to 0.35 . The extension of the lower limit simplifies the implementation of the method by reducing the number of samples to be taken again with other ratios of extraction.

In these conditions, the volume of the reagent was $100 \mathrm{~mL}$, with a concentration of Cohex ion of 5 cmol+ $\cdot L^{-1}$. The suspension was shaken for $2 \mathrm{~h}$ at $20{ }^{\circ} \mathrm{C}$, then filtered on acid-washed and low filtration speed filter paper. With a test sample of $5 \mathrm{~g}$, the acceptable CEC values fell between 5 and 35 $\mathrm{cmol}+\cdot \mathrm{kg}^{-1}$. Sample masses of 10 and $2 \mathrm{~g}$ were used to extend the ranges between 2.5 and $5.0,35$ and 87.5 cmol $+\mathrm{kg}^{-1}$, respectively, according to our previous remarks. 


\section{Method M2: successive extractions}

In this case, the exchange is carried out by shaking the sample three times in the reagent that is renewed at each agitation. We used a test sample of $2.5 \mathrm{~g}$, which was shaken for $2 \mathrm{~h}$ at $20^{\circ} \mathrm{C}$ in the presence of $50 \mathrm{~mL}$ of a solution containing $5 \mathrm{cmol}+\cdot \mathrm{L}^{-1}$ of Cohex ion. The suspension was then centrifuged at $3000 \mathrm{~g}$ for 10 min so as to obtain a perfectly clear supernatant. This operation was repeated twice, thus yielding three extracts, which were mixed together, after pipetting an equal volume of each of them.

\section{Method M3: percolation}

In this method, the exchange is effected by making the reagent pass through a test sample of known mass. The extract is then collected and analyzed. Samples of 2.5 $g$ were treated with four successive additions of reagent, containing $5 \mathrm{cmol}+\mathrm{L}^{-1}$ of Cohex ion, representing a total volume of slightly less than $75 \mathrm{~mL}$. The percolation was carried out in a tube (fig 1) identical to that described in the AFNOR X 31-150 standard for the determination of the CEC by ammonium acetate. Before the measurement, the extracts were adjusted with the initial solution to a final volume of $75 \mathrm{~mL}$.

\section{Statistical methods}

When a given procedure $(\mathrm{A})$ is repeated twice on a series of samples and the values obtained compared by means of a linear regression, the residual standard deviation $S_{\mathrm{r}(\mathrm{AA})}$ results specifically from the metrological variability. When two different procedures (A and B) are compared in the same way, the residual standard deviation $S_{\mathrm{r}(\mathrm{AB})}$ includes both metrological and methodological variabilities. If the variances $S_{r(A A)}^{2}$ and $S^{2} r(A B)$ are not statistically distinct (using a Snedecor $F$ test), we can consider the procedures as metrologically equivalent and, as a consequence, interchangeable apart from the regression coefficient. To some extent, $\mathrm{S}_{\mathrm{r}(\mathrm{AB})}$ is linked to the coefficient of determination $r^{2}$ and from experience, in this work, methods will still be considered as interchangeable when $r^{2}>0.995$

Metrological equivalence is not easily reached; nevertheless, a close linear correlation without any particular behaviour among the samples tested can allow a linear transposition of the diagnostic scales of each method. Good linear relations suggest that the same physicochemical mechanisms are brought into play with a comparable intensity of their effects on the observed parameters. Accordingly, we shall use the terms of equivalence or equivalent whenever they relate to a physicochemical equivalence and when two conditions are satisfied: a determination coefficient close to 0.95 and the absence of any outlying result within the population observed. This last particularity can be tested by means of standardized residuals, a method proposed by Tomassone et al (1992).

\section{RESULTS AND DISCUSSION}

\section{Comparison of the measurement methods}

The 48 soil samples were extracted according to method Ml. The residual Cohex ion contents were determined according to the measurement methods previously described. Figure 2 shows the relationship obtained.

The slopes estimated in regressions of the type $\mathrm{Y}=\mathrm{AX}$ vary between 0.993 and 1.006 according to which two techniques are being considered. The residual standard deviation in the range of $0.6 \mathrm{cmol}+\cdot \mathrm{kg}^{-1}$ is low, determination coefficients $\left(r^{2}\right)$ are higher than 0.997 , allowing us to conclude that the methods are interchangeable. For the remainder of this study we have chosen to use direct spectrocolorimetry because of its better repeatability, which represents a major advantage in a back titration method.

Whatever the technique of measurement employed, the following remarks should be taken into account.

When the separation of the solid and liquid phase after exchange is imperfect, colloidal particles in suspension may be present. As these are saturated in Cohex ions, the measurements, particularly in flame atomic absorption spectrometry, will be inaccurate.

The Cohex ions are slightly fixed on paper filters. It is wise to keep this fact in mind and to carry out control tests on blanks. One can also centrifuge the suspensions and then filter them on commercially obtained membranes $(0.45 \mu \mathrm{m})$; in this case, adsorption is generally negligible.

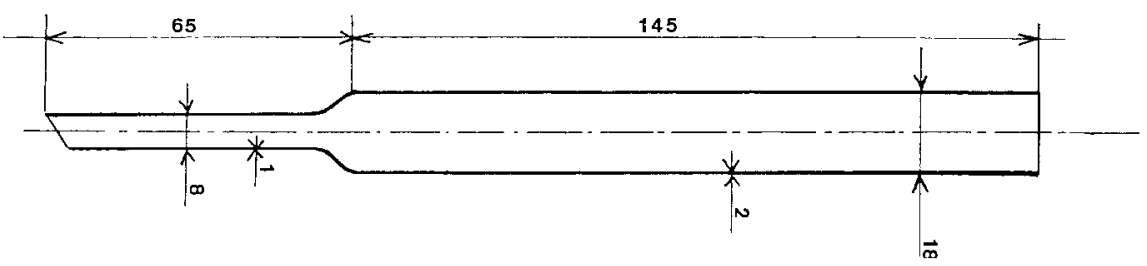

Fig 1. Tube for percolation. 


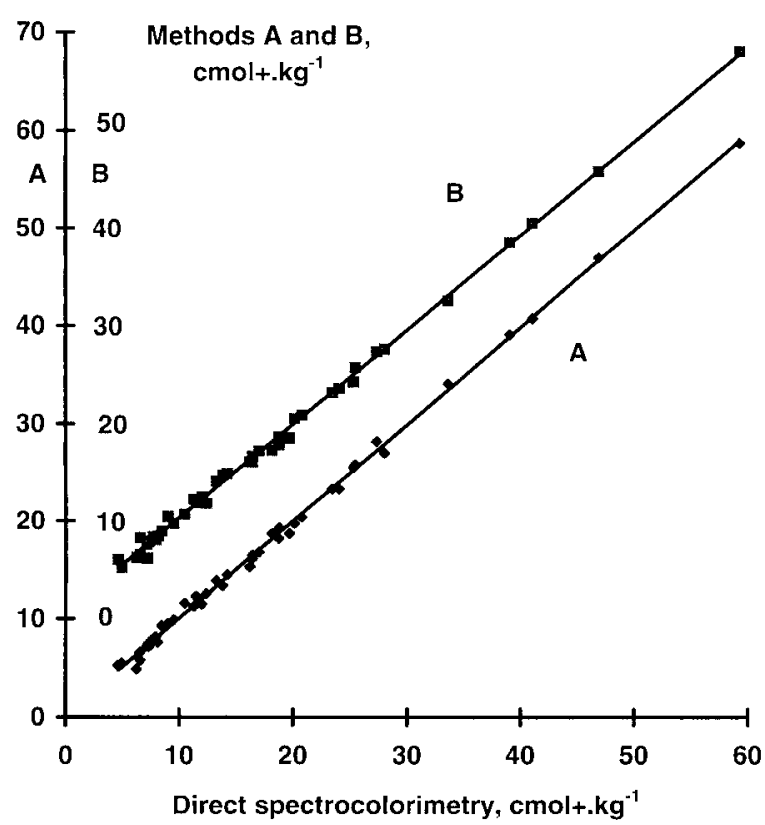

Fig 2. Relationship between cation exchange capacity (CEC) values determined by direct spectrocolorimetry of cobalt hexamine ions and values obtained with the determination of cobalt by flame atomic absorption spectrometry (method $\mathrm{A}$ ) or with spectrocolorimetry of ammonium (method B).

\section{Comparison of the different exchange methods}

The three methods of exchange described were applied to our series of 48 soil samples. In order to compare the values thus obtained for CEC, extracted cations and their saturation rates, we adopt the hypothesis of a linear regression with a zero Y-intercept; the sought relations are thus of the form $\mathrm{Y}=\mathrm{AX}$. Table II lists the slopes (A), the coefficients of determination $\left(r^{2}\right)$ for pairs of methods and the residual standard deviations $\left(\mathrm{S}_{\mathrm{r}}\right)$ The values obtained by single extraction are considered as independant variables (M1).

The experimental CEC values increase with the number of extractions. Comparing the single extraction (M1) and successive extraction (M2) methods, we find a slope of A1 = 1.121 (fig 3). The percolation method (M3) falls in the middle $(\mathrm{A} 2=1.069)$.

The quantities of magnesium extracted from successive extractions and percolation appear identical, and both are superior to those obtained from single extraction (A1 $=1.156$ and $\mathrm{A} 2=$ 1.124). These variations are similar to those for the CEC, yielding roughly similar saturation rates and regression line slopes close to one $(\mathrm{A} 1=$ 1.001 and $\mathrm{A} 2=1.029$ ) (fig 4).

The amount of potassium extracted also increases with the number of extractions (A1 = 1.334) (fig 5), with the percolation method giving intermediate results $(\mathrm{A} 2=1.262)$. These differences are compensated in part by those of the CEC when we take into account the saturation rates. The comparison of these parameters produces regression coefficients which approach unity $(\mathrm{A} 1=1.169$ and $\mathrm{A} 2=1.176)$, but nevertheless remain above it. This shift between extracted potassium and the CEC can be interpreted as resulting from the extraction of fixed forms not quantitatively replaced by the index cation, and depending on the volume of reagent used for a given quantity of soil. This last effect is not specific to Cohex chloride. It has been already noted with ammonium acetate (Quemener and Bosc, 1988).

Table II. Comparison of cation exchange capacity (CEC) and exchangeable cations obtained with different extraction procedures using a linear regression passing through the origin.

\begin{tabular}{|c|c|c|c|c|c|c|c|c|c|}
\hline \multirow[b]{2}{*}{ Units } & \multirow{2}{*}{$\frac{C E C}{c m o l+k g^{-1}}$} & \multicolumn{2}{|c|}{ Magnesium } & \multicolumn{2}{|c|}{ Potassium } & \multicolumn{2}{|c|}{ Calcium (acid soils) } & \multicolumn{2}{|c|}{ Calcium (all soils) } \\
\hline & & $\mathrm{cmol}+\cdot \mathrm{kg}^{-1}$ & $\% C E C$ & $\mathrm{cmol}+\cdot \mathrm{kg}^{-1}$ & $\% C E C$ & $\mathrm{cmol}+\mathrm{kg}^{-l}$ & $\% C E C$ & $\mathrm{cmol}+\mathrm{kg}-$ & $1 \% C E C$ \\
\hline $\mathrm{M} 2=$ & $\begin{array}{l}\mathrm{A} 1=1.121 \\
r^{2}=0.991\end{array}$ & $\begin{array}{l}\mathrm{A} 1=1.156 \\
r^{2}=0.990\end{array}$ & $\begin{array}{l}\mathrm{Al}=1.001 \\
r^{2}=0.952\end{array}$ & $\begin{array}{l}\mathrm{A} 1=1.334 \\
r^{2}=0.987\end{array}$ & $\begin{array}{l}\mathrm{A} 1=1.169 \\
r^{2}=0.958\end{array}$ & $\begin{array}{l}\mathrm{A} 1=1.176 \\
r^{2}=0.983\end{array}$ & $\begin{array}{l}\mathrm{Al}=1.046 \\
r^{2}=0.942\end{array}$ & $\begin{array}{l}\mathrm{A} \mathrm{l}=1.22 \mathrm{l} \\
r^{2}=0.966\end{array}$ & $\begin{array}{l}\mathrm{Al}=1.112 \\
r^{2}=0.912\end{array}$ \\
\hline $\mathrm{Al} \times \mathrm{M} 1$ & $\mathrm{~s}_{\mathrm{r}}=1.32$ & $s_{r}=0.11$ & $\mathrm{~s}_{\mathrm{r}}=0.99$ & & $\mathrm{~s}_{\mathrm{r}}=0.59$ & & $\mathrm{~s}_{\mathrm{r}}=5.1$ & $\mathrm{~s}_{\mathrm{r}}=2.74$ & $\mathrm{~s}_{\mathrm{r}}=11.4$ \\
\hline $\begin{array}{l}\mathrm{M} 3= \\
\mathrm{A} 2 \times \mathrm{M} 1\end{array}$ & $\begin{array}{l}\mathrm{A} 2=1.069 \\
r^{2}=0.986 \\
\mathrm{~s}_{\mathrm{r}}=1.58\end{array}$ & $\begin{array}{l}\mathrm{A} 2=1.124 \\
r^{2}=0.990 \\
s_{\mathrm{r}}=0.10\end{array}$ & $\begin{array}{l}\mathrm{A} 2=1.029 \\
r^{2}=0.976 \\
\mathrm{~S}_{\mathrm{r}}=0.73\end{array}$ & $\begin{array}{l}\mathrm{A} 2=1.262 \\
r^{2}=0.969 \\
s_{\mathrm{r}}=0.06\end{array}$ & $\begin{array}{l}\mathrm{A} 2=1.176 \\
r^{2}=0.973 \\
\mathrm{~s}_{\mathrm{r}}=0.48\end{array}$ & $\begin{array}{l}\mathrm{A} 2=1.117 \\
r^{2}=0.986 \\
\mathrm{~s}_{\mathrm{r}}=0.49\end{array}$ & $\begin{array}{l}\mathrm{A} 2=1.031 \\
r^{2}=0.939 \\
\mathrm{~s}_{\mathrm{r}}=4.7\end{array}$ & $\begin{array}{l}\mathrm{A} 2=1.046 \\
r^{2}=0.986 \\
\mathrm{~s}_{\mathrm{r}}=1.56\end{array}$ & $\begin{array}{l}\mathrm{A} 2=0.994 \\
r^{2}=0.952 \\
\mathrm{~s}_{\mathrm{r}}=6.5\end{array}$ \\
\hline
\end{tabular}

M1: single extraction; M2: successive extractions; $\mathrm{M} 3$ : percolation. $\mathrm{Cmol}+\cdot \mathrm{kg}^{-1}$ : values related to soil; \% CEC: values related to $\mathrm{CEC} ; \mathrm{A} 1$ and A2: regression coefficients; $r^{2}$ : determination coefficients; $\mathrm{s}_{\mathrm{r}}$ : residual standard error. 


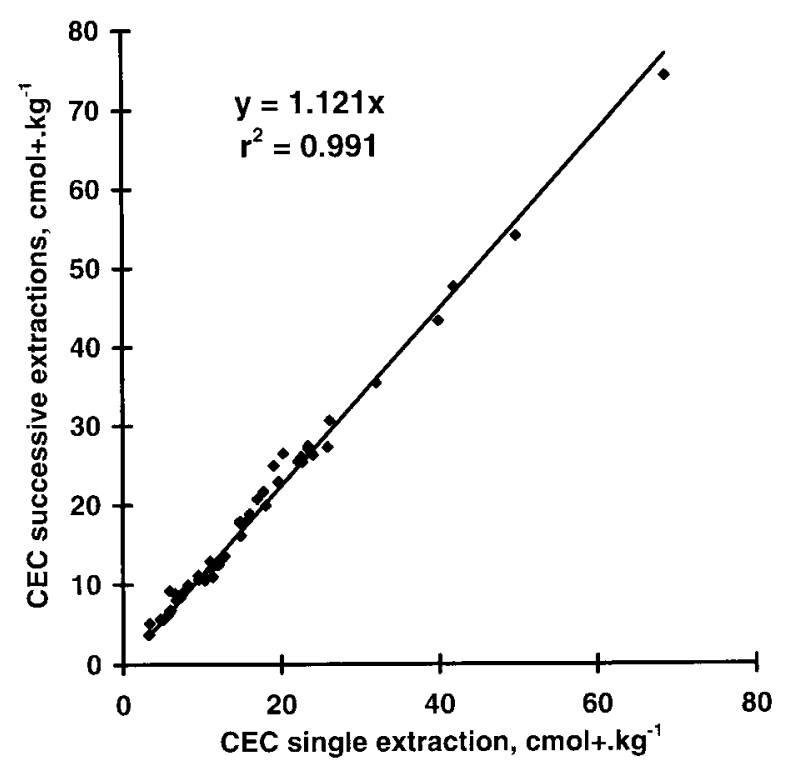

Fig 3. Relationship between cation exchange capacity (CEC) values obtained with a single extraction and three successive extractions.

For calcareous soils, calcium issued from exchangeable as well as from carbonate form can be found in the extracts. In the latter case, the part in solution will be linked to the nature of the carbonated materials and will prove to be sensitive to experimental conditions; for a given quantity of soil, the greater the volume of the reagent, the higher the quantities dissolved. Consequently, results are less closely related when saturation rates for $\mathrm{M} 1$ and $\mathrm{M} 2$ are compared $\left(r^{2}=0.912\right)$. When only acid soils are

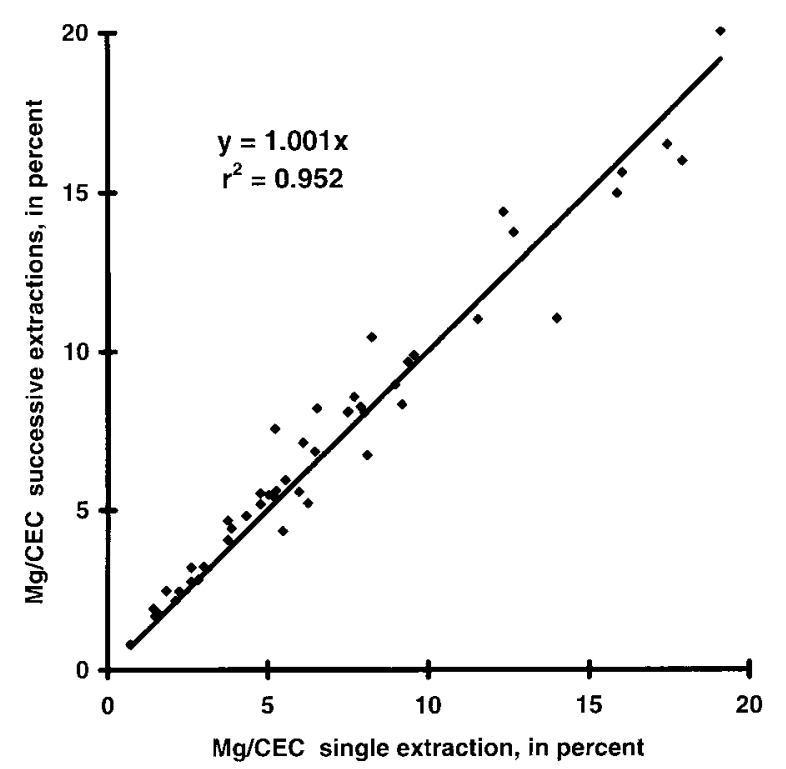

Fig 4. Relationship between magnesium saturation rates obtained by single extraction and three successive extractions. considered, calcium behaves similarly to magnesium $(\mathrm{A} 1=1.176$ and $\mathrm{A} 2=1.117)$ and the comparison of the saturation rates gives values of $\mathrm{A} 1=1.046$ and $\mathrm{A} 2=1.031$.

All these observations can be confirmed in a different way by means of successive extractions. This procedure allows individual measurements of the solubilized quantities in each extract. Considering our population of soils, mean values of the amount extracted after each operation expressed as a fraction of the total amount extracted are calculated (table III). Values for CEC, magnesium and calcium (for acid soils) show similar patterns, whereas potassium and calcium behave differently (for calcareous soils) as shown earlier.

The high determination coefficients $\left(r^{2}\right)$ given in table II allow us to admit the equivalence of the three methods tested with the exception of calcium saturation rates and particularly for calcareous soils (A1 $\left.=1.112, r^{2}=0.912\right)$. Such a particular behaviour results rather from the dissolution of calcareous species than from a distinctive progress of the exchange reaction.

The preceding considerations show that the methods are not interchangeable and, unfortunately, in the present study there is no parameter concerned with metrological equivalence. Ensuring a closer convergence of values thus requires the use of a single method. The choice of method must take into account the ease of implementation, the rapidity and, of

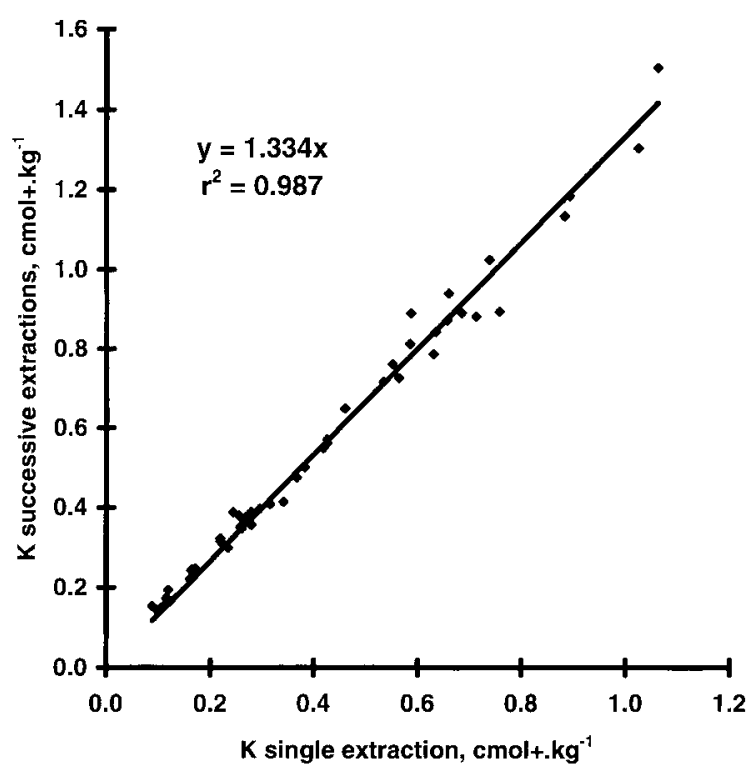

Fig 5. Relationship between exchangeable potassium (K) contents obtained with a single extraction and three successive extractions. 
course, the cost. All these criteria lead to the choice of a single extraction method which remains rigorous as compared with more sophisticated ones.

\section{CONCLUSION}

This study shows the validity of a direct spectrocolorimetric determination of the Cohex ion which, moreover, improves repeatability of the measurements. The comparison of the different exchange procedures leads us to conclude that the nature of the physicochemical mechanisms brought into play and the magnitude of their incidence on the observed parameters, with the exception of saturation rates for calcium, particularly for calcareous soils, are equivalent. This equivalence, however, does not imply that the methods are interchangeable in metrological respects. After considering different criteria, we finally recommend the use of single extractions for routine analysis.

From a certain level, improving the yield of the exchange reaction does not fundamentally modify the scale of the obtained values which remain comparable apart from a coefficient close to one. For most applications disadvantages, such as the dissolution of non-exchangeable species or the use of more complicated and time-consuming procedures, exceed the scientific interest of a slightly better yield.

\section{REFERENCES}

Chapman HD (1965) Cation exchange capacity. In Methods of Soil Analysis (CA Black et al, eds), Agronomy (Madison) 9, 891-901

Fallavier P, Babre D, Breysse M (1985) Détermination de la capacité d'échange cationique des sols tropicaux acides. Agron Tropi 40-4, 298-308

Table III. Successive extractions. Cation exchange capacity (CEC) and exchangeable cations measured in each extract and expressed as a fraction of the total value. Mean values of 48 soils.

$\mathrm{Ca} \quad \mathrm{Ca}$

Extract CEC Mg $\quad$ M acid soils calcareous soils

\begin{tabular}{llllll}
\hline $1^{\text {st }}$ & 0.882 & 0.880 & 0.735 & 0.891 & 0.792 \\
$2^{\text {nd }}$ & 0.082 & 0.068 & 0.165 & 0.067 & 0.125 \\
$3^{\text {rd }}$ & 0.036 & 0.052 & 0.100 & 0.042 & 0.083 \\
\hline
\end{tabular}

Gillman GP, Bruce RC, Davey BG, Kimble JM, Searle PL, Skjemstad JO (1983) A comparison of methods used for determination of cation exchange capacity. Commun Soil Sci Plant Anal 14, 1005-1014

Gray HB (1969) Les électrons et la liaison chimique. Ediscience, Paris, France, 168-198

Guadalix ME, Pardo MT, Hernando V (1988) Evaluation of cation exchange capacity measurements for variable charge soils. Commun Soil Sci Plant Anal 19, 271-279

Morais FI, Page AL, Lund LJ (1976) The effect of pH, salt concentration, and nature of electrolytes on the charge characteristics of Brazilian tropical soils. Soil Sci Soc Am J 40, 524-527

Morel R (1957) Etude expérimentale des phénomènes d'échange sur différents minéraux argileux. Ann Agron (Paris) 8, 5-90

Metson AJ (1956) Methods of chemical analysis for soil survey samples. $N$ Z Soil Bur Bull $\mathrm{n}^{\circ} 12$

Orsini L, Remy JC (1976) Utilisation du chlorure de cobaltihexammine pour la détermination simultanée de la capacité d'échange et des bases échangeables des sols. Sci Sol 4, 269-275

Quemener J, Bosc M (1988) Remarques sur la détermination du potassium échangeable. In: Phosphore et potassium dans les relations sol/plante. Éditions INRA, Paris, France, 109-132

Rhoades JD (1982) Cation exchange capacity. In: Methods of Soil Analysis (AL Page et al, eds) Agronomy (Madison) 9, 149-157

Riehm, Ulrich B, Ulrich M (1954) Schnelle bestimmung der kationensorption kapacitat. Landwirtsch Forsch 6, 2-95

Tomassone R, Audrain S, Lesquoy-de Turckheim E, Millier C (1992) La régression, nouveaux regards sur une ancienne méthode statistique. Inra et Masson, Paris, France, 24-29

\section{STANDARDS}

Norme AFNOR NFX 31-103 (1988) Détermination du $\mathrm{pH}$ dans l'eau.

Norme AFNOR X 31-107 (1983) Analyse granulométrique par sédimentation.

Norme AFNOR NFX 31-108 (1992) Détermination des cations extractibles par l'acétate d'ammonium.

Norme AFNOR NFX 31-109 (1993) Détermination du carbone organique par oxydation sulfochromique.

Norme AFNOR NFX 31-130 (1993) Détermination de la capacité d'échange cationique et des cations extractibles. 